\title{
I. GREETINGS OF THE CHAIRMAN OF THE VERKHOVNA RADA OF UKRAINE
}

\section{Andrii Parubii}

To the staff members of S. P. Timoshenko Institute of Mechanics, the NAS of Ukraine

Dear friends,

Congratulations on the 100th Anniversary of the S. P. Timoshenko Institute of Mechanics of the NASU!

The previous century was marked by a flurry of scientific achievements, a rapid technological advance, which was to a great extent enhanced by the research and development work of the National Academy of Sciences of Ukraine, and by the achievements of Ukrainian scientists. The Institute of Mechanics established at the same time as the National Academy of Sciences, contributed considerably to the development of the global science and proving Ukraine to be a state with a great research and development capabilities.

The world famous scientists worked at the Institute, including Stephan Timoshenko, Dmitriy Grave, Mykola Bogolyubov, Yurii Mitropolskyi, and many others. The Institute's findings have been recognized worldwide and used in a number of industries.

The Institute has always been in the avant-garde of the research-and-development progress, encouraging the growth of aerospace industries, mechanical engineering, power industry, and defense capabilities of our state. The scientists which are a part of the staff and who have world recognition have solved a lot of very difficult fundamental and applied problems, developed new analytical and numerical methods for design of many structural elements.

Today, when our country is living through hard times you are doing all in your power to strengthen the scientific potential of our country, educate talented young scientists who are to shape the future independent and prosperous Ukraine.

I wish you all good health, personal happiness, and fruitful creative work in the name of our great Motherland!

S. P. Timoshenko Institute of Mechanics, National Academy of Sciences of Ukraine, 3 Nesterova St., Kyiv, Ukraine 03057, e-mail: guz@carier.kiev.ua. Translated from Prikladnaya Mekhanika, Vol. 55, No. 1, pp. 5-25, January-February, 2019. 